\title{
CHANGING INDICATIONS FOR PENETRATING KERATOPLASTY IN THE WEST OF SCOTLAND FROM 1970 TO 1995
}

\author{
A. S. RAMSAY, W. R. LEE and A. MOHAMMED \\ Glasgow
}

\begin{abstract}
SUMMARY
In an attempt to predict the trends which might occur in the changing patterns of corneal surgery in the next decade and hence the financial implications, a retrospective study of the treatment of corneal disease was carried out using the pathological reports issued during the last 25 years in the West of Scotland Ophthalmic Pathology Service. This is a supra-regional specialist service which covers the major population areas in Scotland, although most of the specimens were submitted by consultants in the teaching hospitals in Glasgow. The major indications for surgery in the 1486 specimens received were post-inflammatory scarring (387 cases), repeat penetrating keratoplasty (309), keratoconus (257), Fuchs' dystrophy (120) and secondary endothelial failure after cataract surgery (158). In the past 6 years the indications changed and the commonest indications were secondary endothelial failure and post-inflammatory scarring. The study demonstrates a regional difference when compared with other reports and highlights the increasing demand for penetrating keratoplasty and the consequent resource implications.
\end{abstract}

The indications for penetrating keratoplasty (PK) have continually changed since the technique was introduced, ${ }^{1-12}$ and the availability of donor tissue coupled with the success in post-operative management has resulted in a steady increase in the number of surgical interventions. Previous reports $3,8,11,12$ have identified the four commonest indications for the procedure as keratoconus, repeat PK, 'secondary endothelial failure following cataract surgery' and Fuchs' dystrophy. However, these studies have either been performed outside the United Kingdom ${ }^{3,8,11}$ or have examined more recent indications for PK. ${ }^{12} \mathrm{It}$ is therefore of interest to analyse the changes which

Correspondence to: Professor W. R. Lee, Tennent Institute of Ophthalmology, Western Infirmary, Church Street, Glasgow G11 6NT, UK. Fax: +44 (141) 3397485. have taken place in PK procedures over the last 25 years in one region within the UK. The data represent the diagnosis made on pathological information related to, but not necessarily dependent on, the clinical diagnoses made before surgery.

\section{MATERIALS AND METHODS}

A retrospective analysis of pathology reports of corneal specimens received in the West of Scotland Ophthalmic Pathology Service following PK from 1970 to 1995 was undertaken. As a routine the corneal discs were fixed in buffered glutaraldehyde $(2.5 \%)$ and in the case of rarer disorders, such as the endothelial or stromal dystrophies, tissue samples were studied by scanning and transmission electron microscopy. For routine diagnostic work the corneal discs were bisected and tissue blocks were processed through paraffin. Sections were routinely stained with haematoxylin and eosin, periodic acid-Schiff and Masson trichrome. The current investigation utilised the pathological reports on file, but whenever the clinical diagnosis was not fully consistent with the pathological findings, the clinical notes were obtained in order to obtain precise clinical details concerning the pre-operative diagnosis and the nature of any previous surgical intervention.

The incidence of the five major diagnostic groups keratoconus, secondary endothelial failure, repeat PK, Fuchs' dystrophy and post-inflammatory disease - was reported for each year. In the case of repeat $\mathrm{PK}$, each specimen was counted rather than each patient. In the cases of coincidental findings, e.g. Fuchs' dystrophy and previous lens surgery, the former abnormality was the adopted classification. Non-specific post-inflammatory scarring, often with secondary lipid keratopathy, was commoner in the first decade in the study and was in the majority of cases presumed to be due to a pre-existing herpes simplex infection, although a significant proportion of cases were the sequel of measles or were 
Table I. Indications for penetrating keratoplasties in the west of Scotland from 1970 to 1995 . The numbers of specimens in each category have been grouped into 5-year periods apart from 1995, which is shown separately

\begin{tabular}{|c|c|c|c|c|c|c|c|}
\hline Period & Repeat PK & Keratoconus & $\begin{array}{c}\text { Fuchs' } \\
\text { dystrophy }\end{array}$ & $\begin{array}{l}\text { Secondary } \\
\text { endothelial } \\
\text { failure }\end{array}$ & $\begin{array}{c}\text { Post- } \\
\text { inflammatory } \\
\text { scarring }\end{array}$ & $\begin{array}{c}\text { Other } \\
\text { miscellaneous } \\
\text { indications }\end{array}$ & Total \\
\hline $1970-4$ & $\begin{array}{c}41 \\
(29 \%)\end{array}$ & $\begin{array}{c}18 \\
(13 \%)\end{array}$ & $\begin{array}{c}2 \\
(1 \%)\end{array}$ & $\begin{array}{c}7 \\
(5 \%)\end{array}$ & $\begin{array}{c}47 \\
(33 \%)\end{array}$ & $\begin{array}{c}27 \\
(19 \%)\end{array}$ & 142 \\
\hline $1975-9$ & $\begin{array}{c}67 \\
(24 \%)\end{array}$ & $\begin{array}{c}34 \\
(12 \%)\end{array}$ & $\begin{array}{c}17 \\
(6 \%)\end{array}$ & $\begin{array}{c}5 \\
(2 \%)\end{array}$ & $\begin{array}{c}96 \\
(42 \%)\end{array}$ & $\begin{array}{c}55 \\
(20 \%)\end{array}$ & 274 \\
\hline $1980-4$ & $\begin{array}{c}74 \\
(23 \%)\end{array}$ & $\begin{array}{c}49 \\
(15 \%)\end{array}$ & $\begin{array}{c}37 \\
(11 \%)\end{array}$ & $\begin{array}{c}12 \\
(4 \%)\end{array}$ & $\begin{array}{c}94 \\
(29 \%)\end{array}$ & $\begin{array}{c}62 \\
(19 \%)\end{array}$ & 328 \\
\hline $1985-9$ & $\begin{array}{c}58 \\
(19 \%)\end{array}$ & $\begin{array}{c}62 \\
(21 \%)\end{array}$ & $\begin{array}{c}25 \\
(8 \%)\end{array}$ & $\begin{array}{c}55 \\
(18 \%)\end{array}$ & $\begin{array}{c}70 \\
(23 \%)\end{array}$ & $\begin{array}{c}32 \\
(11 \%)\end{array}$ & 302 \\
\hline $1990-4$ & $\begin{array}{c}58 \\
(16 \%)\end{array}$ & $\begin{array}{c}82 \\
(23 \%)\end{array}$ & $\begin{array}{c}32 \\
(9 \%)\end{array}$ & $\begin{array}{c}63 \\
(17 \%)\end{array}$ & $\begin{array}{c}63 \\
(17 \%)\end{array}$ & $\begin{array}{c}67 \\
(18 \%)\end{array}$ & 365 \\
\hline 1995 & $\begin{array}{c}11 \\
(15 \%)\end{array}$ & $\begin{array}{c}12 \\
(16 \%)\end{array}$ & $\begin{array}{c}7 \\
(9 \%)\end{array}$ & $\begin{array}{c}16 \\
(21 \%)\end{array}$ & $\begin{array}{c}17 \\
(22 \%)\end{array}$ & $\begin{array}{c}12 \\
(16 \%)\end{array}$ & 75 \\
\hline Total & $\begin{array}{l}309 \\
(21 \%)\end{array}$ & $\begin{array}{l}257 \\
(17 \%)\end{array}$ & $\begin{array}{l}120 \\
(8 \%)\end{array}$ & $\begin{array}{l}158 \\
(7 \%)\end{array}$ & $\begin{array}{l}387 \\
(26 \%)\end{array}$ & $\begin{array}{l}255 \\
(17 \%)\end{array}$ & 1486 \\
\hline
\end{tabular}

The numbers of specimens in each category have been grouped into 5-year periods apart from 1995, which is shown separately.

diagnosed as syphilitic (interstitial) keratitis by the clinician managing the case. Cases submitted as Salzmann's nodular dystrophy were classified as 'post-inflammatory'. The primary stromal dystrophies (granular, lattice and macular) were small in number by comparison with the major groups listed above. Other miscellaneous indications for PK, such as acute pyogenic infection, autoimmune diseases (rheumatoid ulceration, rosacea and marginal ulceration), band keratopathy, malformation and trauma, formed some $20 \%$ within the whole series. Accidental trauma was either mechanical or due to chemical burns. Surgical trauma (e.g. following trabeculectomy as distinct from lens surgery) was rare and was also classified under the single heading of trauma. Surgery subsequent to trauma (e.g. trauma requiring lens extraction) was included within the group of trauma cases.

It was not considered appropriate to review and analyse the nature of the cataract surgery or to identify the nature or location of the intraocular lens implant in this relatively large series. Lamellar keratoplasties and diagnostic biopsies (e.g. Acanthamoeba infection) were not included in this series.

\section{RESULTS}

In total, 1486 specimens were received, with numbers increasing steadily over the 25 year period (Table I). For a broad assessment the data were grouped into 5 year blocks giving both numerical and percentage values; the numbers for 1995 were recorded separately. Overall, the highest cumulative incidence for each specific entity was for post-inflammatory scarring (387), and this was followed by repeat PK (309), keratoconus (257), secondary endothelial failure (158) and Fuchs' dystrophy (120). The total number of grafts performed increased over each 5 year period, showing a fivefold increase from 1970-4 to 1990-4. The contribution of the UK Transplant
Support Service Authority (UKTSSA) to this total was significant (Table II).

The numbers of repeat PKs increased between 1975 and 1985, but declined after this, while PKs performed for keratoconus increased fourfold. There was a striking increase in the number of specimens exhibiting the changes of keratoconus, and in the 5 year period 1990-4 some 82 specimens were received. The number of cases of Fuchs' dystrophy also increased from $2(1 \%)$ in $1970-4$ to $32(9 \%)$ in 1990-4. PKs performed for secondary endothelial failure following cataract surgery showed a ninefold increase from the first study period to the last; this was a greater proportionate increase than any other diagnostic category, rising from 5\% in 1970-4 to $17 \%$ in 1990-4. In 1995 this indication was recorded as $21 \%$ of the total and was similar in incidence to the specimens classified as post-inflammatory scarring.

\section{DISCUSSION}

The study can be regarded as comprehensive. because it has been standard practice in the West of Scotland for ophthalmic surgeons to submit all keratoplasty discs for pathological examination dur-

Table II. Corneal transplants in the West of Scotland as reported to the UKTSSA from 1 January 1984 to 31 December 1994

\begin{tabular}{lccc}
\hline Year & $\begin{array}{c}\text { West of } \\
\text { Scotland }\end{array}$ & $\begin{array}{c}\text { Glasgow } \\
\text { hospitals }\end{array}$ & Total \\
\hline 1984 & 1 & & 1 \\
1985 & 1 & 3 & 4 \\
1986 & 3 & 7 & 10 \\
1987 & 1 & 6 & 7 \\
1988 & 14 & 10 & 24 \\
1989 & 13 & 23 & 36 \\
1990 & 32 & 32 & 64 \\
1991 & 22 & 37 & 59 \\
1992 & 26 & 49 & 75 \\
1993 & 39 & 82 & 121 \\
1994 & 46 & 82 & 128 \\
Total & 198 & 331 & 529 \\
\hline
\end{tabular}


ing the past 25 years. The data therefore provide a reasonable representation of the changes which have occurred between 1970 and 1995, and interesting trends have been observed. In common with other reports, a steady increase in the number of PKs has been described, with the annual rate almost doubling within the United Kingdom and the USA. ${ }^{2,12}$ This reflects a spread in familiarity with the technique, improvements in instrumentation and provision of well-preserved donor tissue (see Table II). In the present study the cumulative totals of PK indications rank 'post-inflammatory scarring' as the most common indication, followed by 'repeat PK', keratoconus, secondary endothelial failure and Fuchs' dystrophy. In the period 1985-95 these indications for surgery were similar to those in other studies, which listed either 'secondary endothelial failure following cataract surgery' $1-3,8,9,11,12$ or keratoconus $^{5,6,10}$ as the most common indications for surgery.

While repeat PK represented one of the more common indications for surgery overall and increased by $50 \%$ from the beginning to the end of the study period, there was a relative decline when considered as a proportion of total PKs performed (from $29 \%$ to $16 \%$ ). Repeat PK would be expected to represent a smaller proportionate workload if the individual grafts had a longer survival. Information was not sought in the present study regarding the length of graft survival, but it is interesting to speculate that it may have lengthened as the contributing clinicians became aware of the reduced chance of graft survival associated with a diagnosis of inflammatory disease such as herpes simplex keratitis. Some North American studies, however, have shown regrafts to be on the increase, ${ }^{1,2,11}$ although Brady and associates ${ }^{9}$ report a stabilisation in numbers.

PKs for keratoconus became more numerous throughout the study period, increasing almost one and a half times as much as the total number of grafts. It is of interest that this occurred despite improvements in medical management of the condition with gas-permeable contact lenses. Indeed Brady et al. ${ }^{9}$ found a decrease in the incidence of PKs for keratoconus between 1983 and 1988 which was attributed to this change in management. In our series keratoconus, which is now regarded as a common condition with good success rates following PK, became the most common indication between 1985 and 1995. Mamalis et al. ${ }^{10}$ also reported keratoconus overtaking regrafting as the most common indication in 1990, despite a stable incidence of grafts for Fuchs' dystrophy.

There was an eighteenfold rise in PKs performed for Fuchs' dystrophy between 1970-4 and 1990-4, with a stabilisation at about $10 \%$ of the total in the past two decades. The prevalence of this diagnosis in an ageing population would not be expected to have been determined by an increasing volume of cataract surgery on patients in whom the diagnosis of Fuchs' dystrophy was either originally missed or regarded as insignificant. The good response of this disease to PK may have increased the surgeons' readiness to operate on such patients in Scotland. In the USA, Mamalis et al. ${ }^{10}$ reported stable numbers of grafts for Fuchs' dystrophy.

We regard the change in incidence for PKs performed for endothelial failure secondary to cataract surgery as a major feature of our study. Over the whole period of study this diagnosis rose by a factor of 9, with a fivefold increase since 1980-4. This represents a larger proportionate rise in more recent years than in any other diagnostic process, although the numbers have not yet overtaken others under consideration. This is in contrast to other studies where secondary endothelial failure is not only the most common indication for $\mathrm{PK}^{1-3,8,9,11,12}$ but is actually thought to be decreasing since $1987 .{ }^{10}$ These differences may reflect regional differences in techniques of cataract surgery. Phacoemulsification is an unlikely explanation as it has not been in widespread use in the West of Scotland. The use of iris-fixated and anterior chamber intraocular lens implants may have contributed but would not explain the more rapid rise after 1980 as the use of these implants was far less common. The explanation could lie in the sheer bulk of cataract surgery now performed in an increasingly elderly population, despite an awareness of factors and procedures that should protect the corneal endothelium.

Diagnostic inaccuracies or coding uncertainties were a potential source of error in this investigation. In our study whenever the clinical diagnosis was not fully supported by pathological examination, the clinical and pathological records were compared. A common source of difficulty was in separating Fuchs' dystrophy from endothelial failure secondary to cataract surgery. In some cases Fuchs' dystrophy was not noted prior to cataract surgery and the pathological information was of value in the further management of such cases. This problem was also encountered by other investigators. ${ }^{3,13}$ The policy in this study was to classify the primary disorder as Fuchs' dystrophy where both factors were present, even though neither was cited on the request form as the primary cause of endothelial failure. This redefinition may have contributed to the large apparent increase in cases grafted in treatment of Fuchs' dystrophy.

In terms of an audit this study has shown that the number of penetrating keratoplasties performed has continually increased while the indications for surgery have altered. Should the demand for treat- 
ment continue to rise, re-allocation of significant resources will be required. However, it is likely that national and regional differences in practice and referral will be affected by the future management of corneal disease and the incidence of cataract surgery. ${ }^{1-3,6-13}$

\section{REFERENCES}

1. Mohamadi P, McDonnell JM, Irvine JA, McDonnell PJ, Rao N, Smith RE. Changing indications for PK, 1984-88. Am J Ophthalmol 1989;107:550-2.

2. Robin JB, Gindi JJ, Koh K, Schanzlin DJ, Rao NA, York KK, Smith RE. An update of the indications of PK 1979 through 1983. Arch Ophthalmol 1986;109: 87-9.

3. Smith RE, McDonald R, Nesburn AB, Minckler DS. Penetrating keratoplasty: changing indications, 1947 to 1978. Arch Ophthalmol 1980;98:1226-9.

4. Kwartz J, Leatherbarrow B, Dyer P, Ridgway AEA, Tullo AB. Penetrating keratoplasty for pseudophakic corneal oedema. Br J Ophthalmol 1995;79:435-8.

5. Lindquist TD, McGlothan JS, Rotkis WM, Chandler
JW. Indications for PK: 1980-1988. Cornea 1992;10: 210-6.

6. Morris RJ, Bates AK. Changing indications for keratoplasty. Eye 1989;3:455-9.

7. Sharif KW, Casey TA. Changing indications for PK, 1971-1990. Eye 1993;7:485-8.

8. Hyman L, Wittpenn J, Yang C. Indications and techniques of penetrating keratoplasties, 1985-1988. Cornea 1992;11:573-6.

9. Brady SE, Rapuano CJ, Arentsen JJ, Cohen EJ, Laibson PR. Clinical indications for and procedures associated with PK, 1983-1988. Am J Ophthalmol 1989;108:118-22.

10. Mamalis N, Anderson CW, Kreisler KR, Lundergan MK, Olson RJ. Changing trends in the indications for PK. Arch Ophthalmol 1992;110:1409-11.

11. Rapuano CJ, Cohen EJ, Brady SE, Arentsen JJ, Laibson PR. Indications for and outcomes of repeat PK. Am J Ophthalmol 1990;109:689-95.

12. Vail A, Gore SM, Bradley BA, Easty DL, Rogers CA. Corneal transplantation in the United Kingdom and Republic of Ireland. Br J Ophthalmol 1993;77:650-6.

13. Lindquist TD, McNeill JI, Wilhelmus KR. Indications for keratoplasty. Cornea 1994;13:105-7. 